TAP CHI SINH HOC 2020, 42(1): 21-29

DOI: $10.15625 / 0866-7160 / \mathrm{v} 42 \mathrm{n} 1.13833$

\title{
EXPRESSION OF GENE ENCODING FLAVONOL SYNTHASE ISOLATING FROM TRUNG DU XANH TEA (Camellia sinensis var. macrophylla) IN E. coli
}

\author{
Hoang Thi Thu Yen ${ }^{1, *}$, Vu Thi Lan ${ }^{1}$, Huynh Thi Thu Hue ${ }^{2}$ \\ ${ }^{1}$ University of Sciences, Thai Nguyen University, Thai Nguyen, Vietnam \\ ${ }^{2}$ Institute of Genome Research, VAST, Vietnam
}

Received 20 May 2019, accepted 10 January 2020

\begin{abstract}
Common flavonols in plants including quercetin, kaempferol and myricetin are synthesized from dihydroflavonols (dihydroquercetin-DHQ, dihydrokaempferol-DHK and dihydromyricetinDHM) by flavonol synthase (FLS). In tea, FLS has been shown to metabolize dihydroquercetin to quercetin. The FLS gene was cloned and sequenced from the cultivated tea (Camellia sinensis var. macrophylla) in Thai Nguyen province. In this study, we presented the results of optimizing and designing an expression vector for recombinant FLS (recombinant FLS-rFLS). The FLS gene was ligated completely to the pET32a (+) vector, then expressed in E. coli Rosetta1 and Rosetta 2 strain. Using $1 \mathrm{mM}$ IPTG to induce the expression of rFLS at $37^{\circ} \mathrm{C}, \mathrm{rFLS}$ was obtained with $52.83 \mathrm{kDa}$ in size and existed predominantly as insoluble form. E. coli Rosetta1 pET32a (+)_FLS produces rFLS in the soluble fraction than E. coli Rosetta2 pET32a $(+)_{-} F L S$. Next, E c coli Rosetta1 pET32a (+) FLS was optimized for expression at temperatures of $30^{\circ} \mathrm{C}, 23^{\circ} \mathrm{C}$ and $16^{\circ} \mathrm{C}$ ( 24 and 48 hours). After being induced for expression with $1 \mathrm{mM}$ IPTG in 48 hours and cultured at $16^{\circ} \mathrm{C}$, E. coli Rosetta1 strain containing pET32a (+) FLS produced the largest amount of rFLS in the soluble form.
\end{abstract}

Keywords: Camelia sinensis, dihydroquercetin metabolism, flavonol synthase, recombinant FLS.

Citation: Hoang Thi Thu Yen, Vu Thi Lan, Huynh Thi Thu Hue, 2020. Expression of gene encoding flavonol synthase isolating from trung du xanh tea (Camellia sinensis var. macrophylla) in E. coli. Tap chi Sinh hoc, 42(1): 21-29. https://doi.org/10.15625/0866-7160/v42n1.13833.

*Corresponding authoremail: yenhtt@tnus.edu.vn

(C2020 Vietnam Academy of Science and Technology (VAST) 


\title{
BIỂU HIỆN GEN MÃ HÓA FLAVONOL SYNTHASE PHÂN LẬP TƯ CHË TRUNG DU XANH (Camellia sinensis var. macrophylla) TRONG VI KHUẨN E. coli
}

\author{
Hoàng Thị Thu Yến ${ }^{1, *}$ Vũ Thị Lan', Huỳnh Thị Thu Huệa \\ 'Đại học Khoa học, Đại học Thái Nguyên, Thái Nguyên, Việt Nam \\ ${ }^{2}$ Viện Nghiên cứu hệ gen, Viện Hàn lâm Khoa học và Công nghệ Việt Nam
}

Ngày nhận bài 20-5-2019, ngày chấp nhận 10-1-2020

\section{TÓM TẮT}

Các flavonol phổ biến ở thực vật bao gồm quercetin, kaempferol và myricetin, được tổng hợp từ các dihydroflavonols (dihydroquercetin-DHQ, dihydrokaempferol-DHK và dihydromyricetin DHM) bởi flavonol synthase (FLS). Ở chè, FLS được chứng minh có hoạt tính chuyển hóa dihydroquercetin thành quercetin. Gen $F L S$ đã được tạo dòng và xác định trình tự từ giống chè trung du xanh được trồng ở Thái Nguyên. Trong nghiên cứu này, chúng tôi trình bày kết quả thiết kế vector và tối ưu biểu hiện FLS tái tổ hợp (recombinant FLS-rFLS). Vector pET32a(+)_FLS đã được tạo thành công mang cấu trúc biểu hiện FLS và được biểu hiện trong vi khuẩn $E$. coli Rosetta1 và E.coli Rosetta2. Sử dụng IPTG $1 \mathrm{mM}$ cảm ứng biểu hiện $\mathrm{rFLS}$ ở $37^{\circ} \mathrm{C}, \mathrm{rFLS}$ thu được có kích thước $52,83 \mathrm{kDa}$, tồn tại chủ yếu ở dạng không tan. Trong đó, chủng $E$. coli Rosetta1 pET32a(+)_FLS tạo rFLS biểu hiện ở dạng tan nhiều hơn chủng $E$. coli Rosetta2 pET32a(+)_FLS. Tiếp theo, chủng $E$. coli Rosetta1 pET32a $(+)_{-} F L S$ được tối ưu biểu hiện ở các nhiệt độ $30^{\circ} \mathrm{C}$, $23^{\circ} \mathrm{C}$ và $16^{\circ} \mathrm{C}\left(24\right.$ và 48 giờ). Cảm ứng IPTG $(1 \mathrm{mM})$ sau 48 giờ nuôi ở $16^{\circ} \mathrm{C}$, chủng $E$. coli Rosetta1 chứa pET32a(+)_FLS tạo rFLS lượng lớn ở pha tan.

Từ khóa: Chè, chuyển hóa dihydroquercetin, flavonol synthase, FLS tái tổ hợp.

*Địa chỉ liên hệ email: yenhtt@ tnus.edu.vn

\section{MỞ ĐẦU}

Chất lượng sản phẩm chè được đánh giá chủ yếu dựa trên thành phần hóa học có trong chè. Theo Harbowy (1997), polyphenol là thành phần hóa học chính trong chất rắn chiết xuất từ chè, chiếm 30-40\%. Hàm lượng polyphenol quyết định đến màu sắc, độ chát của nước chè và góp phần tạo hương vị của chè (Harbowy \& Balentine, 1997). Hầu hết các đặc tính có lợi cho sức khỏe con người đã được chứng minh là do các hợp chất polyphenol có trong chè. Các hợp chất polyphenol ở thực vật nói chung và chè nói riêng được tổng hợp thông qua con đường phenylpropanoid và flavonoid (Czemmel et al., 2009; Kim et al., 2014). Các hợp chất tạo ra từ con đường flavonoid (Flavonoid) là các chất chuyển hóa thứ cấp, được tạo ra ở nhiều loại thực vật, có vai trò quan trọng đối với sự tăng trưởng và sinh lý bình thường của thực vật (Pietta, 2000). Cho đến nay, khoảng 10.000 flavonoid khác nhau đã được mô tả, cấu trúc chung của chúng bao gồm hai vòng thơm sáu carbon (vòng $\mathrm{A}$ và $B$ ) và một dị vòng 3 carbon chứa một nguyên tử oxy (vòng $\mathrm{C}$ ). Cấu trúc này có thể được thay đổi bằng cách sắp xếp lại, kiềm hóa, oxy hóa và glycosyl hóa (Turnbull et al., 2004). Sửa đổi vòng $\mathrm{C}$ tạo nên các nhóm phụ flavonoid khác nhau: flavones, flavonols, flavan-3-ols (catechins $\rightarrow$ proanthocyanidins-PAs) và anthocyanin (Cheng et al., 2014). Đáng chú ý là thành phần flavonoid giữa các loài thực vật có thể khác nhau đáng kế, Arabidopsis không 
chứa 5'-hydroxylated flavonoid và PAs nhu được mô tả ở các loài thực vật khác (Abrahams et al., 2002). Các flavonoid được chứng minh là có nhiều lợi ích cho sức khỏe con người như chống oxi hóa, kháng viêm, kháng lại tác nhân gây bệnh và kháng chất gây ung thư (Berger, 2005; Vita, 2005). Con đường sinh tổng hợp các hợp chất flavonoid được các nhà sinh học và hóa học quan tâm do tầm quan trọng của chúng. Do đó, hầu hết các gen mã hóa các enzyme tham gia con đường phenylpropanoid và flavonoid đã được phân lập và nghiên cứu chức năng ở nhiều loài thực vật (Czemmel et al., 2009; He et al., 2018; Kim et al., 2014; Tohge et al., 2017; Winkel-Shirley, 2001) (hình1).

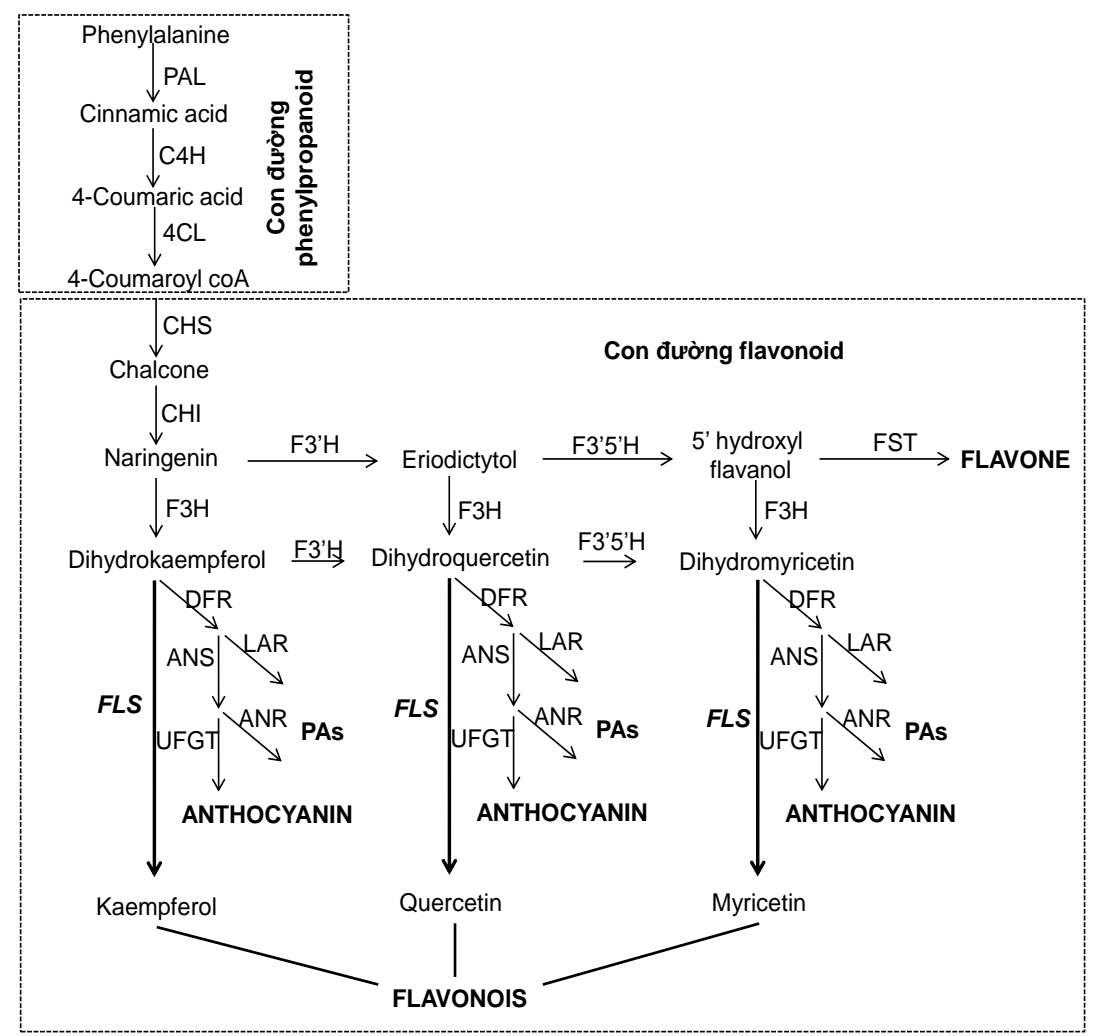

Hình 1. Các con đường có thể sinh tổng hợp các hợp chất flavonol ở chè (Czemmel et al., 2009; Wang et al., 2012)

Ghi chú: ANR (anthocyanidin reductase); ANS (anthocyanin synthase); 4CL (4-coumarate: CoA ligase); $\mathrm{C} 4 \mathrm{H}$ (cinnamate 4-hydroxylase); CHI (chalcone isomerase); CHS (chalcone synthase); DFR (dihydroflavonol reductase); F3H (flavanone 3ß-hydroxylase); F3'H (flavonoid 3'-hydroxylase); F3' 5 'H (flavonoid 3'5'-hydroxylase); FLS (flavonol synthase); FST: flavonol 4-sulfotransferase; LAR (leuacoanthocyanidin reductase); PAL (phenylalanine ammonialyase); proanthocyanidins - PAs; UFGT (UDP-glucoseflavonoid 3-O-glucosyl transferase).

Ở nhiều loài thực vật, flavonol là thành phần có nhiều nhất trong các hợp chất flavonoid và đóng vai trò quan trọng (Havsteen, 2002). Flanovol quy định màu sắc, hương vị, chất lượng và dinh dưỡng của lá, hoa và quả ở thực vật, chúng có khả năng chống viêm, chống oxy hóa, chống đông máu và do đó có lợi cho sức khỏe của con người (Butelli et al., 2008; Havsteen, 2002). Thành phần flavonol ở các loài thực vật có thể bao gồm: quercetin, kaempferol và myricetin (Czemmel et al., 2009; He et al., 2018; Kim et al., 2014). Bằng phương pháp định lượng HPLC, He et al. (2018) chỉ ra ở chè có cả 3 
loại flavonol và tồn tại dưới dạng glycosyl hóa (O-Glycosylated favonols) (He et al., 2018). Favonol là một trong hai thành phần chủ yếu của flavonoid ở chè (Harbowy \& Balentine, 1997) và được cho là có lợi cho một số bệnh mãn tính ở người (McKay \& Blumberg, 2002). Flavonols được tổng hợp từ các dihydroflavonol (dihydroquercetin-DHQ, dihydrokaempferol-DHK và dihydromyricetin-DHM) bởi enzyme flavonol synthase (FLS) (Cheng et al., 2014; Czemmel et al., 2009; Kim et al., 2014). Ngoài ra ở cây họ cải (Arabidopsis thaliana), FLS có thể chuyển đổi naringenin thành dihydrokaempferol. Hoạt tính của FLS được nghiên cứu lần đầu tiên ở mùi tây, hoạt động của FLS cần có sự tương tác với 2oxoglutarate và $\mathrm{Fe}$ (II) (Britsch et al., 1981). Sau đó, FLS đã được nghiên cứu cấu trúc và hoạt tính chức năng từ nhiều loại thực vật như cây dã yên (Petunia hybrida), cây cam nhật (Citrus unshiu), các cây trong họ cải (Arabidopsis thaliana; Matthiola incana), hoa cẩm chướng (Dianthus caryophyllus), nho (Vitis vinifera), chè (Camellia sinensis), ngô (Zea mays), bạch quả (Gingko biloba) (Cheng et al., 2014).

Gen mã hóa cho FLS từ chè trồng ở Hàn Quốc đã được tạo dòng và nghiên cứu biểu hiện ở $E$. coli, FLS tái tổ hợp được chứng minh có hoạt tính chuyển hóa dihydroquercetin thành quercetin (Lin et al., 2007). Chen et al. (2014) cho rằng $\mathrm{FLS}$ là một enzyme đa chức năng (Cheng et al., 2014), chức năng chuyển hóa các dihydroflavonol khác (DHQ, DHK) và naringenin của FLS ở chè chưa được nghiên cứu. Ở Việt Nam, gen mã hóa FLS từ chè Thái Nguyên, giống trung du xanh và trung du tím đã được tạo dòng và phân tích trình tự (Hoang Thi Thu Yen và nnk., 2017). Trong nghiên cứu này, chúng tôi nghiên cứu biểu hiện gen $F L S$ phân lập từ giống chè trung du xanh trong vi khuẩn $E$. coli Rosetta để góp phần nghiên cứu làm sáng tỏ chức năng của FLS ở chè.

\section{VÂT LIỆU VÀ PHƯƠNG PHÁP NGHIÊN CỨU}

Vector tạo dòng pJET1.2_FLS mang gen $F L S$ phân lập từ giống chè trung du xanh và vector biểu hiện $\mathrm{pET} 32 \mathrm{a}(+)$ được lưu giữ tại Phòng Đa dạng Sinh học hệ gen, Viện nghiên cứu Hệ gen, Viện Hàn lâm Khoa học và Công nghệ Việt Nam.

\section{Tạo cấu trúc biểu hiện gen FLS}

Vector pJET1.2_FLS được cắt bằng hai enzyme giới hạn BamHI và $X h o I$ để thu đoạn gen FLS có kích thước 993 bp. Đồng thời, phản ứng cắt bằng $B a m H I$ và $X h o I$ cũng được tiến hành với vector biểu hiện $\mathrm{pET} 32 \mathrm{a}(+)$. Sau đó, phản ứng lai gen $F L S$ vào vector $\mathrm{pET} 32 \mathrm{a}(+)$ sử dụng T4 ligase được tiến hành ở điều kiện $22^{\circ} \mathrm{C}$ trong 1 giờ. Sản phẩm sau đó được biến nạp vào tế bào vi khuẩn $E$. coli $\mathrm{DH} 10 \mathrm{~b}$ bằng phương pháp sốc nhiệt. Khuẩn lạc được chọn lọc trên môi trường LB có bổ sung kháng sinh ampicillin $(50 \mu \mathrm{g} / \mathrm{ml})$. Khuẩn lạc chọn lọc được tiến hành nuôi và tách plasmid, plasmid được kiển tra bằng cắt enzyme giới hạn và PCR với cặp mồi đặc hiệu cho gen FLS (F $\mathrm{F}_{331}$ : 5'GGATCCATGGAGGTAGAGAGAG-3'; F 331: 5'-GGAGCTCTTGTGGAATCTTATTG-3'.

Vector biểu hiện gen $F L S$ tạo ra được kí hiệu là pET32a $(+)_{-} F L S$. Cấu trúc vector pET32a(+)_FLS được mô tả như hình 2.

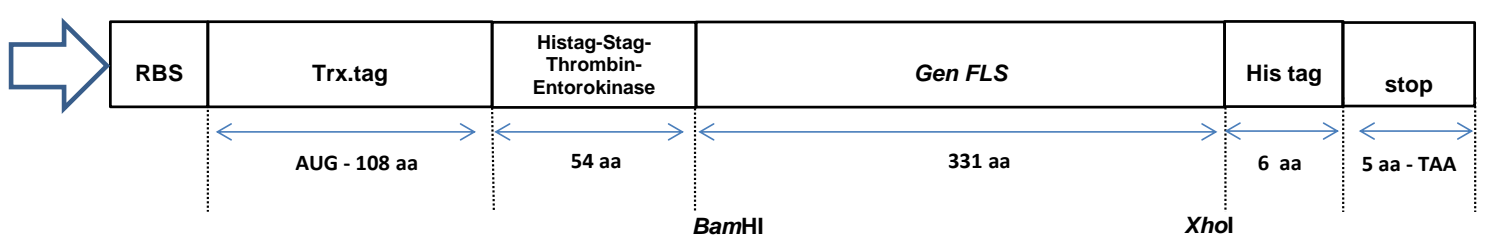

Hình 2. Mô hình cấu trúc biểu hiện gen $F L S$

Ghi chú: RBS: Trình tự nhận biết của ribosome; Trx.tag giúp tăng cường protein tái tổ hợp ở dạng tan trong nước, Histag, Stag là trình tự giúp phát hiện và tinh chế protein tái tổ hợp, Thrombin và Enterokinase là trình tự giúp cắt chuỗi amino acid của protein tái tổ hợp. 


\section{Biểu hiện gen FLS}

Cấu trúc biểu hiện gen mã hóa FLS (pET32a $\left.(+) \_F L S\right)$ được biển nạp vào 2 chủng vi khuẩn là $E$. coli Rosetta1 và $E$. coli Rosetta2 theo phương pháp sốc nhiệt (Novagen). Dịch nuôi tế bào được cấy trải trên đĩa LB có bổ sung kháng sinh ampicillin $(50 \mu \mathrm{g} / \mathrm{ml})$, nuôi qua đêm ở điều kiện $37^{\circ} \mathrm{C}$. Các chủng vi khuẩn được xác nhận chứa cấu trúc biểu hiện bằng PCR khuẩn lạc với cặp mồi đặc hiệu cho gen $F L S\left(\mathrm{~F}_{331}: 5^{\prime}-\right.$ GGATCCATGGAGGTAGAGAGAG-3'; F F31 $^{2}$ 5'-GGAGCTCTTGTGGAATCTTATTG-3').

Tiếp theo, cảm ứng biểu hiện gen $F L S$ trong các chủng biểu hiện ở nồng độ IPTG $1 \mathrm{mM}$ dưới điều kiện $37^{\circ} \mathrm{C}$ trong 5 giờ, các tế bào được thu và xử lý trước khi kiểm tra protein tổng số trên gel polyacrylamide $14 \%$.

\section{Tối ưu biểu hiện FLS tái tổ hợp}

Chủng $E$. coli Rosetta1 chứa cấu trúc biểu hiện pET32a(+)_FLS tạo FLS tái tổ hợp (recombinant FLS - rFLS) được nuôi lắc trong môi trường LB lỏng có bổ sung kháng sinh ampicillin $(50 \mu \mathrm{g} / \mathrm{ml})$ qua đêm. Tiếp theo, dịch nuôi được làm mới trong $8 \mathrm{ml}$ LBA

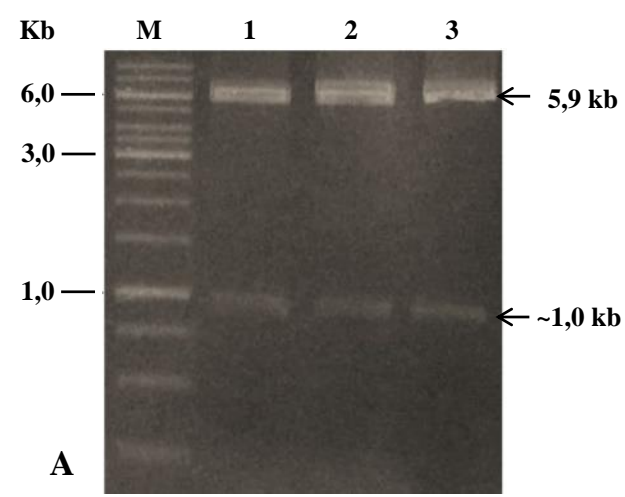

$\left(\mathrm{OD}_{600}=0,1\right)$. Sau 2 giờ nuôi lắc ở $37^{\circ} \mathrm{C}$, dịch khuẩn đạt giá trị từ $\mathrm{OD}_{600}=0,6$ sẽ được cảm ứng biểu hiện với IPTG $1 \mathrm{mM}$ và tiếp tục nuôi ở các điều kiện như sau: $37^{\circ} \mathrm{C}(5$ giờ $), 30^{\circ} \mathrm{C}(6$ giờ $), 23^{\circ} \mathrm{C}(8$ giờ $)$ và $16^{\circ} \mathrm{C}$ (24 giờ và 48 giờ $)$ (Jiang et al., 2013). Thí nghiệm được thực hiện cùng đối chứng $E$. coli Rosetta chứa pET32a $(+) \_F L S$ không cảm ứng IPTG.

\section{KẾT QUẢ VÀ THẢO LUẬN}

\section{Thiết kế vector biểu hiện mang gen FLS}

Vector pJET1.2_FLS được cắt bằng hai enzyme giới hạn BamHI và $X h o \mathrm{I}$ để thu đoạn gen FLS có kích thước 993 bp. Đồng thời, phản ứng cắt bằng $B a m \mathrm{HI}$ và $X h o \mathrm{I}$ cũng được tiến hành với vector $\mathrm{pET} 32 \mathrm{a}(+)$. Tiếp theo, chúng tôi thực hiện phản ứng lai gen $F L S$ vào vector $\mathrm{pET} 32 \mathrm{a}(+)$, biến nạp vào tế bào vi khuẩn $E$. coli $\mathrm{DH} 10 \mathrm{~B}$ và nuôi trên môi trường LB chọn lọc. Chúng tôi lựa ngẫu nhiên một số dòng vi khuẩn để phân tích chọn dòng vi khuẩn mang vector biểu hiện $\mathrm{pET} 32 \mathrm{a}(+) \_F L S$ bằng phản ứng cắt bằng enzyme giới hạn và $\mathrm{PCR}$. Sản phẩm của phản ứng cắt plasmid bằng $B a m H I$ và $X h o \mathrm{I}$ được điện di kiểm tra trên gel agarose $0,8 \%$ (hình $3 \mathrm{~A}$ ).

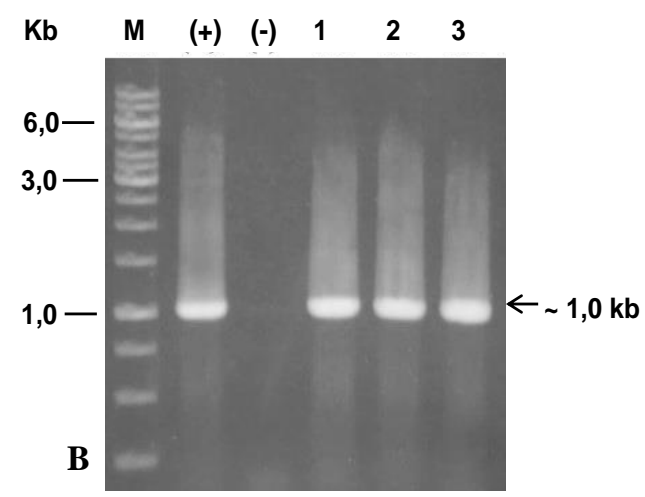

Hình 3. Kết quả điện di kiểm trả sản phẩm cắt kiểm tra plasmid pET32a $(+) \_F L S$ bằng enzyme giới hạn và $\mathrm{PCR}$ khuếch đại gen

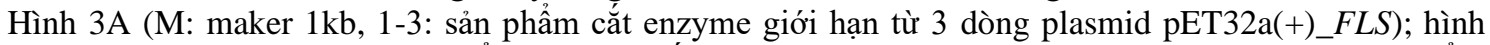
3B $(\mathrm{M}$ : maker $1 \mathrm{~kb},(+)$ : sản phẩm $\mathrm{PCR}$ từ đối chứng dương là plasmid pJET1.2_ $F L S,(-)$ : sản phẩm

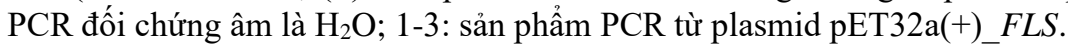

Trên hình 3A cho thấy, plasmid tách chiết được cắt kiểm tra bằng enzyme giới hạn $B a m \mathrm{HI}$ và $X h o \mathrm{I}, \mathrm{DNA}$ plasmid bị cắt thành hai đoạn: một đoạn lớn có kích thước tương ứng với kích thước vector pET32a $(+)(5,9 \mathrm{~kb})$ và một đoạn nhỏ hơn có kích thước khoảng $1,0 \mathrm{~kb}$ tương ứng với đoạn gen $F L S$. Như vậy, chúng tôi đã tạo được vector $\mathrm{pET} 32 \mathrm{a}(+)$ mang gen $F L S$. Đồng thời, phản ứng PCR được thực hiện với cặp mồi nhân gen $F L S$ ở 3 dòng 
plasmid đã kiểm tra bằng enzyme giới hạn. Sản phẩm $\mathrm{PCR}$ từ 3 dòng plasmid đều lên băng đậm và rõ nét có kích thước khoảng 1,0 $\mathrm{kb}$ tương ứng với kích thước của đoạn gen $F L S$ (hình $3 \mathrm{~B}$ ). Như vậy, chúng tôi đã tạo được dòng biến nạp vào $E$. coli $\mathrm{DH} 10 \mathrm{~b}$ mang cấu trúc biểu hiện pET32a(+)_FLS.

\section{Biểu hiện gen $F L S$ trong vi khuẩn $E$. coli}

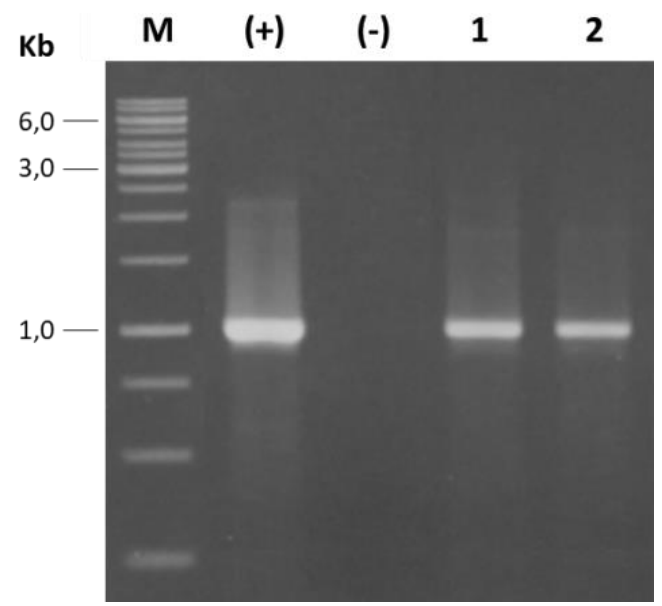

Hình 4. Kết quả kiểm tra sự có mặt của plasmid pET32a $(+) \_F L S$ trong các chủng E. coli biểu hiện

M: maker $1 \mathrm{~kb},(+)$ : sản phẩm PCR từ đối chứng dương là plasmid $\mathrm{pET} 32 \mathrm{a}(+) \ldots L S,(-)$ : sản phẩm PCR đối chứng âm là $\mathrm{H}_{2} \mathrm{O} ; 1-2$ : sản phẩm $\mathrm{PCR}$ với khuôn là khuẩn lạc $E$. coli Rosetta1 và 2 .

FLS là một dioxygenase và thuộc siêu họ 2OG-Fe(II) oxygenase. Enzyme này thực hiện chức năng chuyển hóa dihydroflavonols tạo flavonols thông qua domain đặc trưng của siêu họ 2OG-Fe(II) oxygenase. FLS chỉ có hoạt tính chức năng đầy đủ khi có mặt của $\mathrm{Fe}$ (II) và 2-oxoglutarate. Enzyme này thực hiện chức năng chuyển hóa dihydroflavonol tạo flavonol thông qua domain đặc trưng cho siều họ 2OG-Fe(II) oxygenase bao gồm 95 amino acid (từ vị trí amino acid $199 \rightarrow 291$ ) (Britsch et al., 1981; Lin et al., 2007). Một số nghiên cứu đã chứng minh có 3 motif quyết định đến chức năng của FLS (Lukacin \& Britsch, 1997). Motif PxxxIRxxx-EQP ở đầu N (từ vị trí amino acid $18 \rightarrow 29$ ) quyết định đến hoạt tính của FLS, sự thay đồi trình tự nucleotide ở motif có thể làm mất hoạt tính của FLS. Motif
$\mathrm{CPQ} / \mathrm{RPxLAL}(205 \rightarrow 212)$ là vị trí bám của 2oxoglutarate và vị trí amino acid liên kết với $\mathrm{Fe}(217 \mathrm{H}, 219 \mathrm{D}$ và $273 \mathrm{H})$. FLS suy diễn của giống chè trung $\mathrm{du}$ xanh có motif CPQ/RPxLAL và motif PxxxIRxxx-EQP bảo thủ cao và có duy nhất một vị trí amino acid thay đổi so với trình tự đã công bố $(19 \mathrm{~V} \rightarrow \mathrm{A})$ (Hoang Thi Thu Yen và nnk., 2017). Để tạo cơ sở nghiên cứu làm sáng tỏ hoạt tính của FLS ở chè, chúng tôi tiến hành tạo FLS tái tổ hợp. Sau khi thiết kế thành công, vector tái tổ hợp pET32a $(+) F L S$ được biến nạp vào 2 chủng tế bào biểu hiện là $E$. coli Rosetta1 và E. coli Rosetta2. Tiếp theo, chúng tôi chọn ngẫu nhiên một khuân lạc từ mỗi đĩa, tiến hành tách plasmid và kiềm tra sự có mặt của pET32a $(+) \_F L S$ trong các chủng $E$. coli biểu hiện. Kết quả kiểm tra PCR gen $F L S$ được thể hiện ở hình 4.

Kết quả điện di hình 4 cho thấy, sản phẩm PCR khuếch đại gen $F L S$ từ khuẩn lạc $E$. coli Rosetta 1 và 2 đều lên băng đậm và rõ nét có kích thước khoảng $1,0 \mathrm{~kb}$ tương ứng với kích thước của đoạn gen FLS. Từ hai chủng $E$. coli Rosetta1 và Rosetta2 mang cấu trúc biểu hiện pET32a $(+) \_F L S$, chúng tôi sử dụng IPTG để cảm ứng biểu hiện gen $F L S$. Kết quả kiểm tra protein tổng số được thể hiện ở hình 5 .

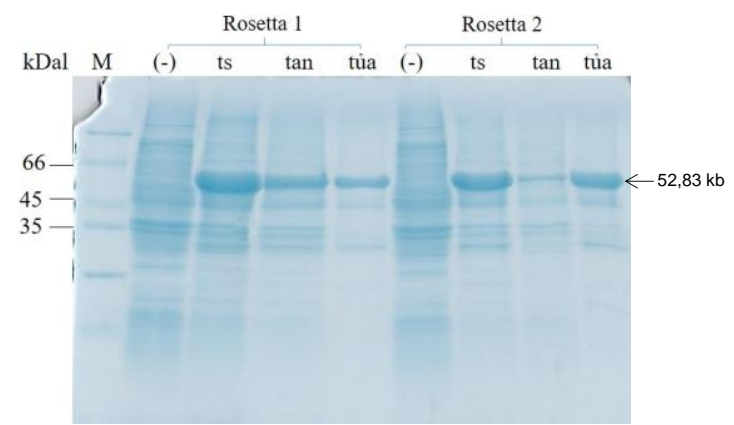

Hình 5. Kết quả điện di sản phẩm protein FLS Ghi chú: M: thang protein chuẩn của Fermentas, (-): đối chứng âm là chủng không được cảm ứng, ts: protein tổng số, tan: protein thu được ở pha tan, tủa: protein thu được ở pha tủa.

Theo tính toán lý thuyết, protein tái tổ hợp thu được có kích thước khoảng $52,83 \mathrm{kDa}$ bao gồm FLS có kích thước khoảng $36,41 \mathrm{kDa}$ cùng với đoạn trình tự TrxA mã hoá cho 
protein thioredoxin $(11,8 \mathrm{kDa})$, His-Taq $(1,68$ $\mathrm{kDa})$, S-Taq $(1,7 \mathrm{kDa})$, thrombin $(0,63 \mathrm{kDa})$ và enterkinase $(0,61 \mathrm{kDa}) \quad(\mathrm{pET}$ System Manual, Novagen). Hình ảnh điện di (hình 5) cho thấy, protein tổng số của các chủng $E$. coli Rosetta1, E. coli Rosetta2 có xuất hiện một băng protein đậm khác biệt so với đối chứng. Băng protein này nằm ở khoảng kích thước tương đương với kích thước trên lý thuyết của protein tái tổ hợp. Trong đó, băng protein ở chủng $E$. coli Rosettal to và đậm hơn so với chủng $E$. coli Rosetta2 thể hiện lượng protein nhiều hơn. Đồng thời chúng tôi cũng đánh giá độ tan của protein tái tổ hợp, chúng tôi nhận thấy rằng chủng biểu hiện $E$. coli Rosetta1, protein FLS biểu hiện ở dạng tan (pha tan) nhiều hơn ở dạng không tan (pha tủa - thể vùi) nhưng sự chênh lệch không quá lớn. Ở chủng biểu hiện $E$. coli Rosetta2, protein FLS hầu hết biểu hiện ở dạng không tan, chỉ một lượng nhỏ ở dạng tan. Sự khác biệt về sự biểu hiện FLS pha tan và tủa ở 2 hai chủng $E$. coli Rosetta1 và Rosetta2 có thể do sự biểu hiện của gen FLS và yếu tố tạo FLS pha tủa ở các chủng biểu hiện không giống nhau. Kết của FLS tái tổ hợp thu được cũng phù hợp với kết quả nghiên cứu biểu hiện gen FLS đã công bố (Lin et al., 2007).

\section{Tối ưu điều kiện nhiệt độ và thời gian để thu rFLS ở pha tan}

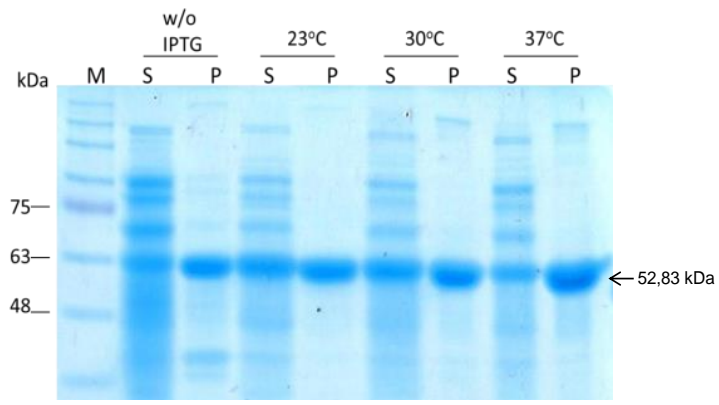

Hình 6. Tối ưu điều kiện nhiệt độ để thu enzyme tái tổ hợp ở pha tan

Ghi chú: w/o IPTG: Đối chứng không cảm ứng IPTG, TS: protein tổng số, $\mathrm{S}$ : protein pha tan, P: protein pha tủa, $\mathrm{M}$ : thang chuẩn protein.

Theo Schein và đtg (1988) (Schein \& Noteborn, 1988), E. coli sinh trưởng và phát triển tốt ở $37^{\circ} \mathrm{C}$. Tuy nhiên, cảm ứng biểu hiện ở $37^{\circ} \mathrm{C}$, protein ngoại lai được tạo ra thường tích lũy ở pha tủa. Trong khi cảm ứng ở 23$30^{\circ} \mathrm{C}, 30-90 \%$ protein tái tổ hợp thu được ở pha tan. Tăng trưởng và cảm ứng ở $25^{\circ} \mathrm{C}$ hoặc $30^{\circ} \mathrm{C}$ có thể là tối ưu nếu sử dụng trình tự peptide tín hiệu của một số vector $\mathrm{pET}$ (Novagen). Chủng E. coli Rosetta1 pET32a(+)_FLS tạo FLS biểu hiện ở dạng tan nhiều hơn chủng $E$. coli Rosetta2 pET32a(+)$F L S$. Do đó, chúng tôi tiến hành tối ưu nhiệt độ biểu hiện rFLS ở chủng $E$. coli Rosetta1 pET32a(+)_FLS (hình 6).

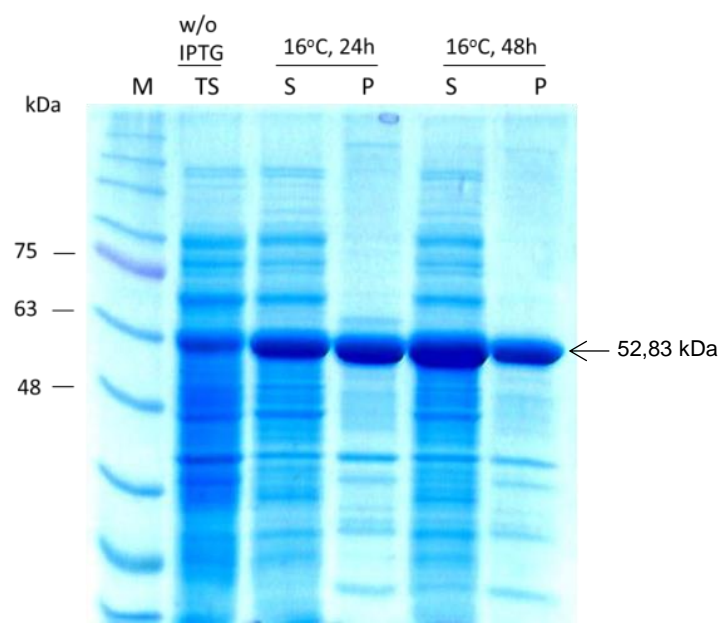

Hình 7. Tối ưu điều kiện thời gian để thu enzyme tái tổ hợp ở pha tan

Ghi chú: w/o IPTG: Đối chứng không cảm ứng IPTG, TS: protein tổng số, S: protein pha tan, P: protein pha tủa, $\mathrm{M}$ : thang chuẩn protein.

Kết quả trên hình 6 cho thấy lượng protein tái tổ hợp có kích thước khoảng $52,83 \mathrm{kDa}$ biểu hiện khá nhiều ở nhiệt độ $37^{\circ} \mathrm{C}, 30^{\circ} \mathrm{C}$ và $23^{\circ} \mathrm{C}$, đó chính là kích thước của rFLS theo tính toán lý thuyết. Ở nhiệt độ càng cao (30 và $37^{\circ} \mathrm{C}$ ), lượng protein thu được càng lớn và càng nhiều ở pha tủa. FLS biểu hiện ở nhiệt độ thấp hơn $\left(23^{\circ} \mathrm{C}\right)$, lượng protein đích ở 2 pha là tương đương nhau. Trong một số trường hợp, cảm ứng kéo dài (qua đêm) ở nhiệt độ thấp $\left(15-20^{\circ} \mathrm{C}\right)$ đã được chứng minh là nhiệt độ tối ưu thu nhận protein pha tan (Novagen). Cảm ứng biểu hiện khi giảm nhiệt độ cũng được chứng minh khi nghiên cứu biểu hiện gen mô hình GFP (Jiang et al., 2013; Schein \& Noteborn, 1988). Mặt khác, 
nghiên cứu của $L i n$ và đtg đã chỉ ra, $E$. coli BL21 chứa pET28a(+) FLS tạo rFLS ở pha hòa tan nhiều hơn khi cảm ứng IPTG ở nhiệt độ $20^{\circ} \mathrm{C}$ so với $30^{\circ} \mathrm{C}$ (Lin et al., 2007). Do đó, chúng tôi lựa chọn nhiệt độ $16^{\circ} \mathrm{C}$ để cảm ứng biểu hiện và thu rFLS sau 24 và 48 giờ cảm ứng. Kết quả kiểm tra protein tổng số được thể hiện ở hình 7.

Kết quả ở hình 7 cho thấy, khi hạ thấp nhiệt độ và kéo dài thời gian biểu hiện, lượng protein không bị giảm đi mà lượng protein ở pha tan còn nhiều hơn pha tủa, đặc biệt khi biểu hiện ở 48 giờ.

\section{KẾT LUÂN}

Gen $F L S$ phân lập từ chè trung $\mathrm{Du}$ xanh được gắn thành công vào vector biểu hiện $\mathrm{pET} 32 \mathrm{a}(+)$ và biến nạp vào vi khuẩn $E$. coli chủng Rosetta1 và Rosetta2. Nuôi các chủng vi khuẩn này ở $37^{\circ} \mathrm{C}$ và sử dụng $\mathrm{IPTG} 1 \mathrm{mM}$ cảm ứng biểu hiện, rFLS thu được có kích thước $52,83 \mathrm{kDa}$, tồn tại ở cả dạng không tan và dạng tan. Trong đó, chủng $E$. coli Rosetta 1 pET32a(+)_FLS tạo rFLS biểu hiện ở dạng tan nhiều hơn chủng $E$. coli Rosetta2 pET32a(+)FLS. Tiếp theo, chủng E. coli Rosetta1 pET32a $(+)_{2} F L S$ được tối ưu biểu hiện ở các nhiệt độ $30^{\circ} \mathrm{C}, 23^{\circ} \mathrm{C}$ và $16^{\circ} \mathrm{C}(24$ và 48 giờ). Sau cảm ứng 48 giờ và nuôi ở $16^{\circ} \mathrm{C}$, chủng $E$. coli Rosetta1 pET32a(+)_FLS tạo rFLS lượng lớn ở pha tan.

\section{TÀI LIỆU THA KHẢO}

Abrahams S., Tanner G. J., Larkin P. J. \& Ashton A. R., 2002. Identification and biochemical characterization of mutants in the proanthocyanidin pathway in Arabidopsis. Plant Physiol., 130(2): 561-576.

Berger M. M., 2005. Can oxidative damage be treated nutritionally? Clinical Nutrition, 24(2): 172-183.

Britsch L., Heller W. \& Grisebach H., 1981. Conversion of Flavanone to Flavone, Dihydroflavonol and Flavonol with an Enzyme System from Cell Cultures of Parsley. Z. Naturforsch, 36(c): 742-750.

Butelli E., Titta L., Giorgio M., Mock H. P., Matros A., Peterek S., Schijlen E. G., Hall
R. D., Bovy A. G., Luo J. \& Martin C., 2008. Enrichment of tomato fruit with health-promoting anthocyanins by expression of select transcription factors. Nat. Biotechnol., 26(11): 1301-1308.

Cheng A. X., Han X. J., Wu Y. F. \& Lou H. X., 2014. The function and catalysis of 2oxoglutarate-dependent oxygenases involved in plant flavonoid biosynthesis. Int J. Mol. Sci., 15(1): 1080-1095.

Czemmel S., Stracke R., Weisshaar B., Cordon N., Harris N. N., Walker A. R., Robinson S. P. \& Bogs J., 2009. The grapevine R2R3-MYB transcription factor VvMYBF1 regulates flavonol synthesis in developing grape berries. Plant Physiol., 151(3): 1513-1530.

Harbowy M. E. \& Balentine D. A., 1997. Tea chemistry. Critical Reviews ill Plant Sciences, 16(5): 415-480.

Havsteen B. H., 2002. The biochemistry and medical significance of the flavonoids. Pharmacol. Ther., 96(2-3): 67-202.

He X., Zhao X., Gao L., Shi X., Dai X., Liu Y., Xia T. \& Wang Y., 2018. Isolation and Characterization of Key Genes that Promote Flavonoid Accumulation in Purple-leaf Tea (Camellia sinensis L.). Sci. Rep., 8(1): 130.

Hoang Thi Thu Yen, Mai Thi Huyen Trang, Pham Thi Hang \& Huynh Thi Thu Hue, 2017. Cloning and sequence analysis off gene encoding flavonol synthase from trung du teas growing in Thai Nguyen. Journal of Science VNU, 33(4): 127-136.

Jiang X., Zhang H., Yang J., Liu M., Feng H., Liu X., Cao Y., Feng D. \& Xian M., 2013. Induction of gene expression in bacteria at optimal growth temperatures. Appl. Microbiol Biotechnol., 97(12): 5423-5431.

Jiang X., Zhang H., Yang J., Liu M., Feng H., Liu X., Cao Y., Feng D. \& Xian M., 2013. Induction of gene expression in bacteria at optimal growth temperatures. Appl. Microbiol. Biotechnol., 97(12): 5423-5431. 
Kim Y. B., Kim K., Kim Y., Tuan P. A., Kim H. H., Cho J. W. \& Park S. U., 2014. Cloning and characterization of a flavonol synthase gene from Scutellaria baicalensis. Scientific World Journal, 2014: 980740.

Lin G. Z., Lian Y. J., Ryu J. H., Sung M. K., Park J. S., Park H. J., Park B. K., Shin J. S., Lee M. S. \& Cheon C. I., 2007. Expression and purification of His-tagged flavonol synthase of Camellia sinensis from Escherichia coli. Protein Expr. Purif., 55(2): 287-292.

Lukacin R. \& Britsch L., 1997. Identification of strictly conserved histidine and arginine residues as part of the active site in Petunia hybrida flavanone 3betahydroxylase. Eur. J. Biochem., 249(3): 748-757.

McKay D. L. \& Blumberg J. B., 2002. The role of tea in human health: an update. $J$ Am. Coll. Nutr., 21(1): 1-13.

Pietta P. G., 2000. Flavonoids as Antioxidants. Joural of Natural Products, 63(7): 1035-1042.

Schein C. H. \& Noteborn M. H. M., 1988. Formation of Soluble Recombinant Proteins in Escherichia Coli is Favored by Lower Growth Temperature. Bio/Technology, 6: 291-294.
Tohge T., de Souza L. P. \& Fernie A. R., 2017. Current understanding of the pathways of flavonoid biosynthesis in model and crop plants. J. Exp. Bot., 68(15): 4013-4028.

Turnbull J. J., Nakajima J., Welford R. W., Yamazaki M., Saito K. \& Schofield C. J., 2004. Mechanistic studies on three 2oxoglutarate-dependent oxygenases of flavonoid biosynthesis: anthocyanidin synthase, flavonol synthase, and flavanone 3beta-hydroxylase. J. Biol. Chem., 279(2): 1206-1216.

Vita J. A., 2005. Polyphenols and cardiovascular disease: effects on endothelial and platelet function. The American Journal of Clinical Nutrition, 81(1): 292-297.

Wang Y. S., Gao L. P., Shan Y., Liu Y. J., Tian Y. W. \& Xia T., 2012. Influence of shade on flavonoid biosynthesis in tea (Camellia sinensis (L.) O. Kuntze). Scientia Horticulturae, 141: 7-16.

Winkel-Shirley B., 2001. Flavonoid biosynthesis. A colorful model for genetics, biochemistry, cell biology, and biotechnology. Plant Physiol., 126(2): 485-493. 